\title{
AN ASSESSMENT OF THE IMPLEMENTATION AND OUTCOMES OF RECENT CHANGES TO FIRE MANAGEMENT IN THE KRUGER NATIONAL PARK
}

\author{
BRIAN W. VAN WILGEN \\ Centre for Invasion Biology \\ CSIR Natural Resources and the Environment \\ South Africa \\ NAVASHNI GOVENDER \\ SANDRA MACFADYEN \\ Scientific Services \\ Kruger National Park \\ South Africa
}

Correspondence to: Brian W. van Wilgen

e-mail: bvwilgen@csir.co.za

Postal Address: Centre for Invasion Biology, CSIR Natural Resources and the Environment, P.O. Box 320, Stellenbosch 7599, South Africa

\begin{abstract}
This paper reviews recent changes in fire management in the Kruger National Park, and assesses the resulting fire patterns against thresholds of potential concern. In 2002, a lightning-driven approach was replaced by an approach that combined point ignitions with unplanned and lightning fires. The approach aimed to burn an annual target area, determined by rainfall and fuel conditions, in point-ignition fires of different sizes. Most of the original fire-related thresholds of potential concern (TPCs) were incorporated into the new approach. The annual target area to be burnt ranged from 12 to $24 \%$ of the park between 2002 and 2006. The total area burnt generally exceeded the targets each year, and management fires accounted for less than half of the total area burnt. The fire regime was dominated by very large fires ( $>5000 \mathrm{ha}$ ) which accounted for $77 \%$ of the total area burnt. New TPCs were developed to assess whether the fire regime encompassed a sufficient degree of variability, in terms of fire intensity and the spatial distribution of burnt areas. After assessment and adjustment, it appears that these TPCs have not yet been exceeded. The point-ignition approach, and its evaluation in terms of variability and heterogeneity, is based on the untested assumption that a diverse fire regime will promote biodiversity. This assumption needs to be critically assessed. We recommend that the practice of point ignitions be continued, but that greater efforts be made to burn larger areas earlier in the season to reduce large and intense dry-season fires.
\end{abstract}

Keywords: adaptive management, biodiversity, elephants, fire regimes, ignition sources

Fire plays a vital role in the coexistence of grass and trees in savanna ecosystems (Higgins et al. 2000, Scholes \& Walker 1993, Van Langevelde $e t$ al. 2003). Despite a growing understanding of the importance of fire, the ways in which it should be managed remain the subject of vigorous debate (Biggs \& Potgieter 1999, Bond \& Archibald 2003, Mentis \& Bailey 1990, Parr \& Andersen 2006, Van Wilgen et al. 2004). Managers of savanna ecosystems have a range of fire-related options available to them, including regular prescribed burning, flexible prescribed burning (both with a range of options regarding return intervals, season and intensity), patch mosaic burning (Brockett et al. 2001), "natural" (lightning-driven) fire regimes (Biggs \& Potgieter 1999), protection from fire, or even a "hands-off" (laissez faire) approach. The choice of an appropriate approach to fire management in savannas is complicated by the differences in responses in moist and arid areas, and in areas of low and high soil fertility - as a result, fire-management approaches developed for specific areas are not universally applicable to others (Bond \& Archibald 2003).

Fire regimes in savannas also display considerable variation over space and time, often tracking variability in annual rainfall and changing levels of herbivory. As a result, the application of inflexible fire policies is not a desirable or practical management option, especially over large areas. The concept of management by "thresholds of potential concern" (hereafter referred to as thresholds) was introduced in the Kruger National Park in the early 1990s (Biggs \& Rogers 2003) to address this problem. Under this framework, upper and lower thresholds were defined for a range of ecosystem indicators. If a threshold is reached, then management interventions are considered; alternately, the threshold could be recalibrated. In line with this policy, thresholds relating to fire patterns were proposed in 1997 (Van Wilgen et al. 1998). Thresholds were assessed using a database of mapped fires, captured on a GIS, and included thresholds relating to fire-return periods, the seasonal distribution of fires, the range of desired fire intensities, and the size-class distribution of fire scars (see Table 1). Exceeding these thresholds would alert managers to potentially undesirable trends in fire regimes, and would trigger assessment and appropriate action.

The system of thresholds for fire management has been in place for a decade now, and considerable experience has been gained in their application and usefulness. In line with the philosophy of adaptive management, these thresholds need to be reviewed and revised (where necessary) in the light of experience gained. In this paper, we review the recent history of firerelated thresholds in the Kruger National Park and their role in the development of a new policy for fire management. We also present an analysis and assessment of the fire patterns that developed under the new policy, and make recommendations for the future management of fire in the park.

\section{The Kruger National Park}

The Kruger National Park (approximately 2 million ha) is situated in the north-eastern corner of South Africa, along the border with Mozambique. The mean annual rainfall varies 
TABLE 1

Fire-related thresholds of potential concern proposed by van Wilgen et al. (1998) and their revised status. The causes for concern are numbered to correspond with the discussion of changes to thresholds of potential concern in the text.

\begin{tabular}{|c|c|c|}
\hline CAUSE FOR CONCERN & ORIGINAL THRESHOLDS PROPOSED & STATUS OF THRESHOLD \\
\hline $\begin{array}{l}\text { 1. Fires do not develop variable long-term patterns with respect } \\
\text { to frequency. }\end{array}$ & $\begin{array}{l}\text { Median fire return period, return periods in long-unburnt areas and } \\
\text { maximum post-fire age to be within given limits. }\end{array}$ & $\begin{array}{l}\text { Abandoned, as fire return periods were found to be governed } \\
\text { by variability in rainfall, and were largely uninfluenced by } \\
\text { management. }\end{array}$ \\
\hline 2. Risk of drought following fire. & Limits of proportion of area burnt in each month. & Abandoned, as limits are built into new management approach. \\
\hline 3. Seasonal distribution of fires to remain within acceptable limits & Ratio of winter to summer burns & $\begin{array}{l}\text { Abandoned, as seasonal burnt area targets are built into new } \\
\text { management approach. }\end{array}$ \\
\hline 4. Narrow range of fire intensities & Proportion of area burnt in high, moderate and low intensity fires & Threshold retained and developed further. \\
\hline 5. Not enough, or too much, fire in a given year. & Limits of progressive proportion of area burnt in a given year. & Abandoned, as limits are built into new management approach. \\
\hline 6. Extremes in fire size may have undesirable effects & Dominance of any particular fire size class & Abandoned, as limits are built into new management approach. \\
\hline 7. Cause of fires & Proportion of area burnt in unplanned fires of human origin. & $\begin{array}{l}\text { Threshold was exceeded in every year, and abandoned as } \\
\text { unworkable in practice. }\end{array}$ \\
\hline
\end{tabular}

between about $350 \mathrm{~mm}$ in the north and about $750 \mathrm{~mm}$ in the south. The vegetation of the park is a well-wooded savanna, in which fires occur regularly during the dry winter season. The rainfall regime is characterised by extended wet and dry periods, in which the rainfall is either higher than the longterm mean, or lower than the mean, for between six and twelve consecutive years. These extended wet and dry periods have marked effects on the occurrence of fires, mainly through their influence on grass fuel loads.

\section{Historical fire management in the park}

Since the proclamation of the park, fire management has passed through a number of phases (see Van Wilgen et al. 2004 for details). These included occasional but limited deliberate burning; attempts to reduce the impacts of fire; both regular and more flexible prescribed burning; and a "natural" fire policy, in which all lightning-ignited fires were allowed to burn freely, while at the same time attempts were made to prevent, suppress or contain all other fires. During the 1990s, a set of seven fire-related thresholds was proposed, with the aim of monitoring and assessing the fire regimes resulting from the natural fire policy that was in place at the time (see Table 1).

The seven initial fire-related thresholds for the Kruger National Park (Van Wilgen et al. 1998) were intended to illustrate the principle of using elements of the fire regime as surrogate measures (of ecosystem health) and as management goals. These surrogate measures were put in place in the absence of more specific guidelines that would enable managers to deal with new paradigms that embraced heterogeneity (Bond \& Archibald 2003). At the time of their development, it was recognised that they would require re-assessment and improvement. The system of thresholds was implemented in the 1990s, and led to a change in fire policy in 2001, as described below.

\section{Changes to the original fire-related thresholds}

The adoption of a new management approach came about as a result of learning from (i) the setting, monitoring and regular assessment of fire-related thresholds, and (ii) research that demonstrated the degree to which fire regimes were determined by factors such as variability in rainfall rather than by management interventions (Van Wilgen et al. 2004). As a result, many of the original fire-related thresholds proposed by Van Wilgen et al. (1998) were either incorporated directly into revised management procedures, or modified as thresholds (see Table 1). This section provides a brief review of these changes; the development of new thresholds is discussed in a later section.

The numbering of thresholds follows Table 1. The first threshold related to variability in fire return periods over time. The concern here was that fixed-interval burning could have had undesired effects in terms of homogenising the environment, as different species would be advantaged by different fire return periods. However, subsequent investigations (Van Wilgen et al. 2004) showed that variability in fire return periods was largely driven by variability in rainfall, and that management had little effect on this outcome. The threshold was therefore regarded as unnecessary and has been discarded.

The second threshold related to the risk of drought following fire, leading to a possible shortage of forage and cover that would be detrimental to herbivores. The threshold set limits to the proportion of area that should be burnt in each month (under a policy of a lightning-driven fire regime), and these proportions were dependent on rainfall. The third threshold related to the seasonal distribution of fires. The concern here was that a concentration of fires in the same season could have had undesired effects in terms of homogenising the environment, as different species would be advantaged by fires in different seasons. The fifth threshold related to the extent of fire in any given year, arising from a concern that too much, or too little, fire could have detrimental effects. The sixth threshold related to fire size distribution, and sought to promote a variety of fire sizes. Again, the rationale was that a variety of fire sizes would promote diversity. All four of these are no longer seen as thresholds, as they have been incorporated as operational procedures in the new management approach.

The fourth threshold, which is related to variability in fire intensity, has been retained, and has been developed further as described below.

The most recent change in fire policy in 2001 came about when the threshold of $25 \%$ of the area burnt in fires caused by humans was exceeded in 1996. Although the cause of fires was considered to have no biological significance, the threshold was included to cater for the policy of promoting a lightning-driven fire regime. Managers first changed the target area from 25 to $50 \%$, then from an annual total to an average over 10 years. However, before the 10-year period had been reached, it became clear that it would in any case be exceeded. Most (> 75\%) of the area that burnt in the 10 years that the lightning policy was in force was burnt in fires not started by lightning.

\section{Current fire management policy in the park}

The current objective of fire management in the Kruger National Park is to ensure the maintenance of this important ecosystem process "in all its facets and fluxes" (Biggs \& Rogers 2003). The policy adopted to achieve this recognises that the effects of fire (especially variable fire regimes) are not fully understood, and the monitoring and assessment of thresholds of potential concern is needed to improve our understanding of the ecological role of fire. This need remains despite considerable research into the ecological role of fire in the park (see Van Wilgen et al. 2007 for a recent review). Once it had become clear that the establishment of a lightning-dominated fire regime was not being realised, the park revised their fire-related objectives. Besides safety considerations, the specific ecological objectives 
within the park are to understand the role of fire as a natural process, and its relationship with other interacting co-drivers, so as to develop an informed context for management. The subobjectives include the need to fill important knowledge gaps with respect to the effects of fire on elements of biodiversity, as well as the use of new understanding to recommend feasible fire-management policies and procedures.

A new management approach was developed which combined the goals of biodiversity conservation with considerations of safety and which recognised the reality of unplanned wildfires. It combines components of patch mosaic burning (Brockett et al. 2001) with "range condition" and "lightning fire" philosophies (see Van Wilgen et al. 1998 for a brief description of these philosophies), while at the same time embracing the reality of numerous unplanned wildfires of human origin. Annual and monthly targets for area burnt are set at the start of each fire season. The targets are based on measurements of standing grass biomass taken at the end of the growing season in March. These target areas increase with increasing biomass; the relationship between grass biomass and the proportion of area to be burned $\mathrm{p}=\{\exp (-3.7+0.00047 \mathrm{~b}) /[1+\exp (-3.7+0.00047 \mathrm{~b})]+\exp$ $(-.47+0.00051 b) /[1+\exp (-2.47+0.00051 b)]\} / 2$, where $\mathrm{p}$ is the proportion of the area to be burned, and $\mathrm{b}$ is the grass biomass in $\mathrm{kg} / \mathrm{ha}$ (Brockett et al. 2001). Each month from early in the fire season, patch fires (using point ignitions) are ignited by rangers. The rangers tasked with implementing the system decide the location of the ignition sites (which they normally place in areas with a high biomass of moribund grasses) and when to ignite fires (on the basis of prevailing weather conditions). Progress (in terms of area burnt) is mapped using MODIS satellite imagery and assessed against targets at the end of each month. These assessments take patch fires and unplanned fires into account, and patch burning ignitions are increased, decreased or

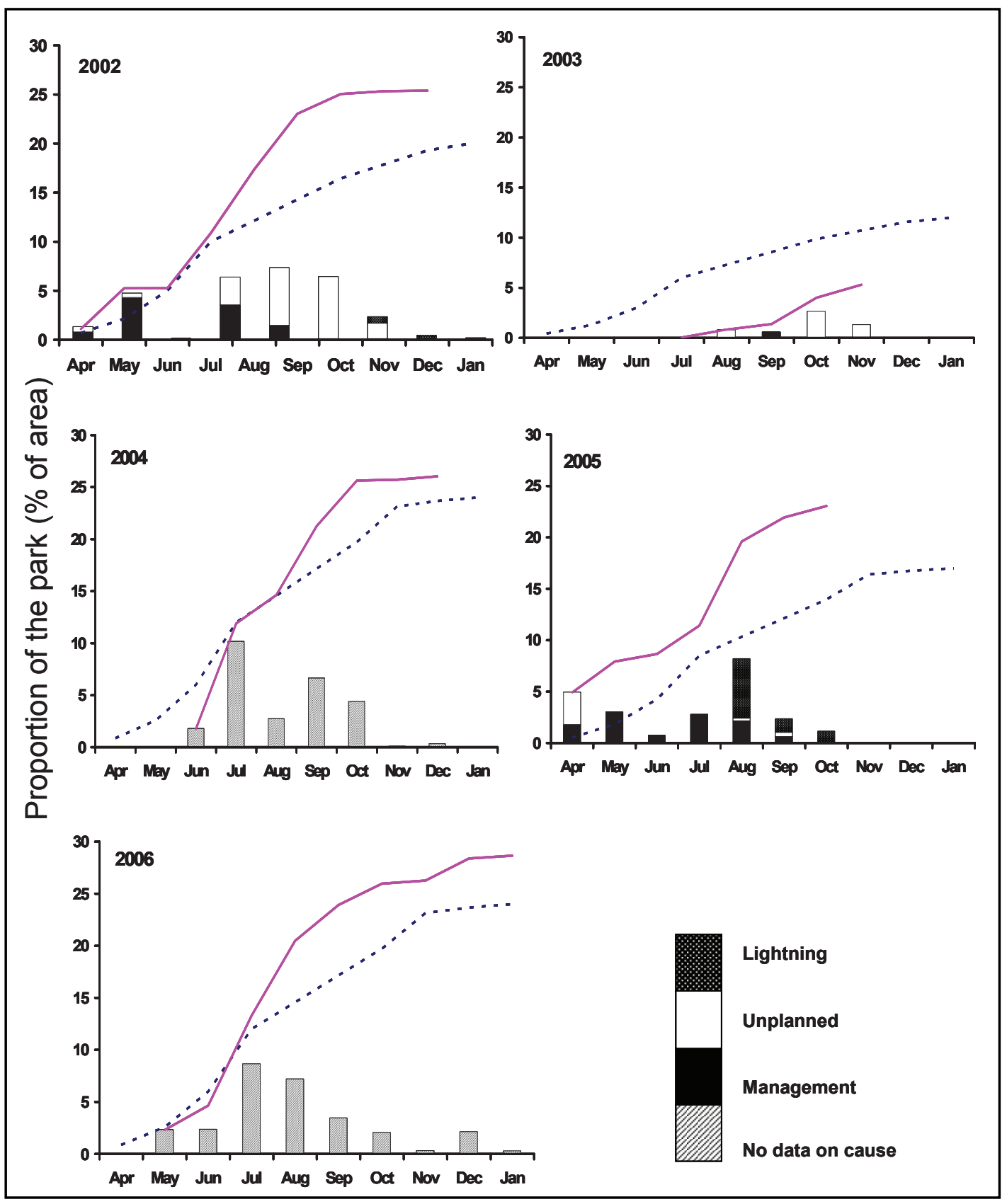

FIGURE

Monthly and cumulative area burnt (expressed as a proportion of the Kruger National Park, 1948000 ha) in five successive years. The dashed line (- - -) shows the cumulative target area, and the solid line (- - ) shows the cumulative actual area burnt. Bars show the monthly area burnt, with cause of fire indicated where data were available. 
suspended depending on progress towards the target. Rangers will generally stop setting fires at the onset of the lightning season (around October), allowing lightning-ignited fires to develop. Unplanned fires are suppressed if they will result in the target area being exceeded.

\section{Implementation of the new fire policy and its outcomes}

This section reports on the fire regimes that were established under the new fire management approach that was implemented in 2002. The target area of the park to be burnt under the new fire policy ranged from $12 \%$ in 2003 to $24 \%$ in 2006 (see Figure 1). With the exception of 2003 , the total area burnt exceeded the targets in each year. Unplanned fires in September and October 2002, and lightning fires (mainly in August) in 2005 resulted in targets being exceeded. In years for which data on the cause of fires are available (2002, 2003 and 2005), management fires accounted for less than half of the total area burnt. Fires were spread across the park, and $69.7 \%$ of the area burned at least once during the five years that the new fire policy was in place (see Figure 2).

The fire-management policy calls for the ignition of patch fires, tolerance of wildfires up to a point, and the encouragement of lightning fires later in the season. In 2002, management fires dominated early in the season, but were replaced by unplanned fires later in the season; the area burnt in lightning-ignited fires was very small (see Figure 1). In 2003, a very small area burned in total, most of it in unplanned fires. In 2005, almost all fires early in the season were planned point ignitions, and these were followed by lightning-ignited fires later in the season. With the exception of some unplanned fires early in the season (in April), this year came the closest to meeting the ignition regime envisaged in the policy. Unfortunately, data on the cause of fires were not available for 2004 and 2006.

The fire regime that was established under the new approach in the park was dominated by very large ( $>5000 \mathrm{ha}$ ) fires (see Tables 2 and 3, Figures 3 and 4). Between 2002 and 2005, these very large fires accounted for between 81 and $88 \%$ of the area burnt; only in 2006 did the area burnt in very large fires fall to $52 \%$. In 2002, 2004 and 2005, large fires dominated from early on in the fire season; it was only in 2006 that smaller fires of between 50 and 5000 ha were able to burn $>30 \%$ of the total area in one year (see Figure 3 and Table 2). The relative dominance of large fires is illustrated by comparison to the patch burning system implemented in the Pilanesberg National Park (Brockett et al. 2001). The number of fires needed to complete annual burning programmes in Pilanesberg (50 000 ha in extent) ranged from 9 (following a dry year, total rainfall $393 \mathrm{~mm}$ ) to 71 (following

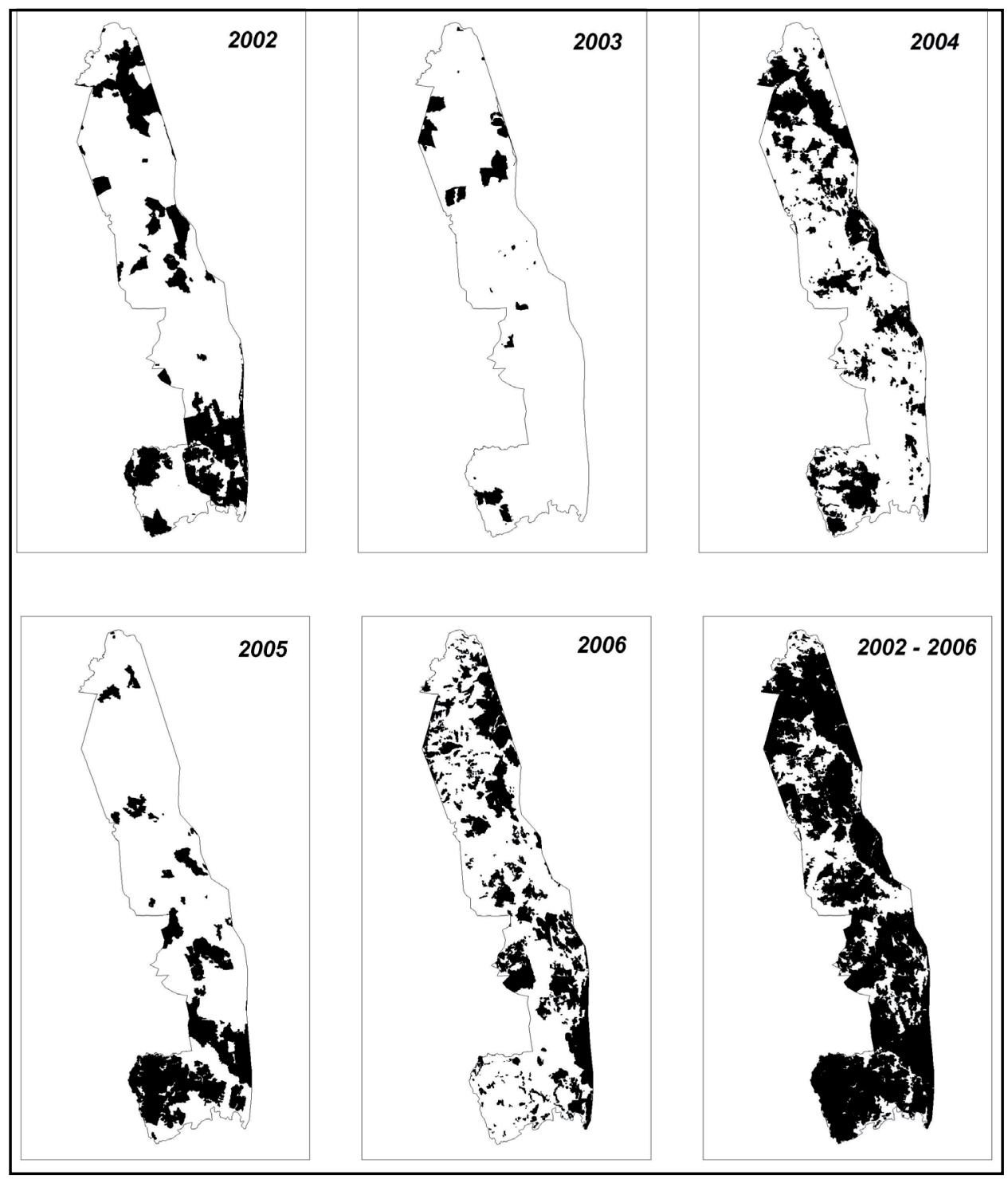

FIGURE 2 
TABLE 2

The area burnt by fires in different size categories following the implementation of a policy of point ignitions in the Kruger National Park between 2002 and 2006

\begin{tabular}{|c|c|c|c|c|c|}
\hline YEAR & FIRE SIZE CLASS (HA) & NUMBER OF FIRES & AREA BURNT (HA) & $\begin{array}{l}\text { PROPORTION OF AREA } \\
\text { BURNT (\%) }\end{array}$ & $\begin{array}{l}\text { NUMBER OF FIRES PER } \\
50000 \text { HA OF THE PARK }\end{array}$ \\
\hline \multirow{5}{*}{2002} & Small $(0-50)$ & 13 & 205 & 0.04 & \\
\hline & Medium $(51-1000)$ & 29 & 8314 & 1.7 & \\
\hline & Large (1001 - 5000) & 23 & 52233 & 10.8 & \\
\hline & Very large (> 5001) & 30 & 421461 & 87.4 & \\
\hline & All fires & 95 & 482213 & 100 & 2.4 \\
\hline \multirow{5}{*}{2003} & Small $(0-50)$ & 8 & 144 & 0.14 & \\
\hline & Medium $(51-1000)$ & 14 & 4114 & 4.0 & \\
\hline & Large (1001 - 5000) & 4 & 10641 & 10.5 & \\
\hline & Very large $(>5001)$ & 7 & 85814 & 85.1 & \\
\hline & All fires & 32 & 100764 & 100 & 0.8 \\
\hline \multirow{5}{*}{2004} & Small $(0-50)$ & 43 & 1583 & 0.03 & \\
\hline & Medium $(51-1000)$ & 127 & 30289 & 6.1 & \\
\hline & Large (1001 - 5000) & 26 & 49956 & 10.0 & \\
\hline & Very large (> 5001) & 14 & 401219 & 81.0 & \\
\hline & All fires & 212 & 494802 & 100 & 5.3 \\
\hline \multirow{5}{*}{2005} & Small $(0-50)$ & 2 & 81 & 0.02 & \\
\hline & Medium $(51-1000)$ & 26 & 8689 & 2.0 & \\
\hline & Large (1001 - 5000) & 12 & 26732 & 6.1 & \\
\hline & Very large (> 5001) & 17 & 385802 & 88.1 & \\
\hline & All fires & 60 & 437887 & 100 & 1.5 \\
\hline \multirow{4}{*}{2006} & Small $(0-50)$ & $\begin{array}{l}76 \\
258\end{array}$ & $\begin{array}{l}2036 \\
76885\end{array}$ & $\begin{array}{l}0.4 \\
15.3\end{array}$ & \\
\hline & Large (1001 - 5000) & $\begin{array}{l}208 \\
65\end{array}$ & 157935 & 31.5 & \\
\hline & Very large (> 5001) & 17 & 264064 & 52.7 & \\
\hline & All fires & 424 & 500920 & 100 & 8.5 \\
\hline
\end{tabular}

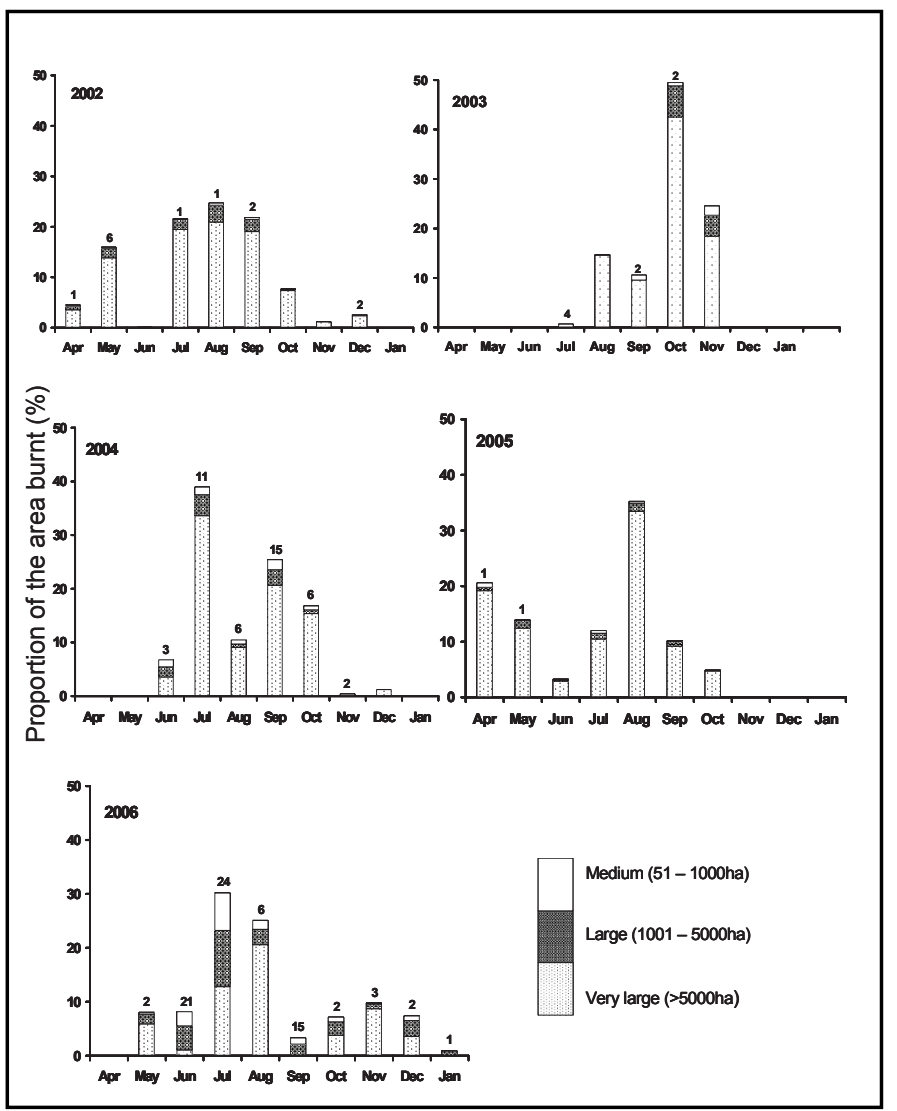

FIGURE 3

Monthly area burnt by fires of different sizes in the Kruger National Park in five successive years (see Table 2 for areas burnt in each year). Numbers above each bar indicate the number of small $(<50 \mathrm{ha})$ fires in each month. The area covered by these small fires is negligible, and is included in the "medium" size category. 
TABLE 3

The mean and maximum size of very large fires $(>5000 \mathrm{ha})$ associated with the implementation of a policy of point ignitions in the Kruger National Park between 2002 and 2006

\begin{tabular}{llll}
\hline YEAR & NUMBER OF FIRES & MEAN AREA (HA) & AREA OF LARGEST FIRE (HA) \\
\hline 2002 & 30 & 14048 & 53799 \\
2003 & 7 & 12259 & 21168 \\
2004 & 14 & 28658 & 149646 \\
2005 & 17 & 22694 & 109842 \\
2006 & 17 & 15533 & 42798 \\
\hline
\end{tabular}

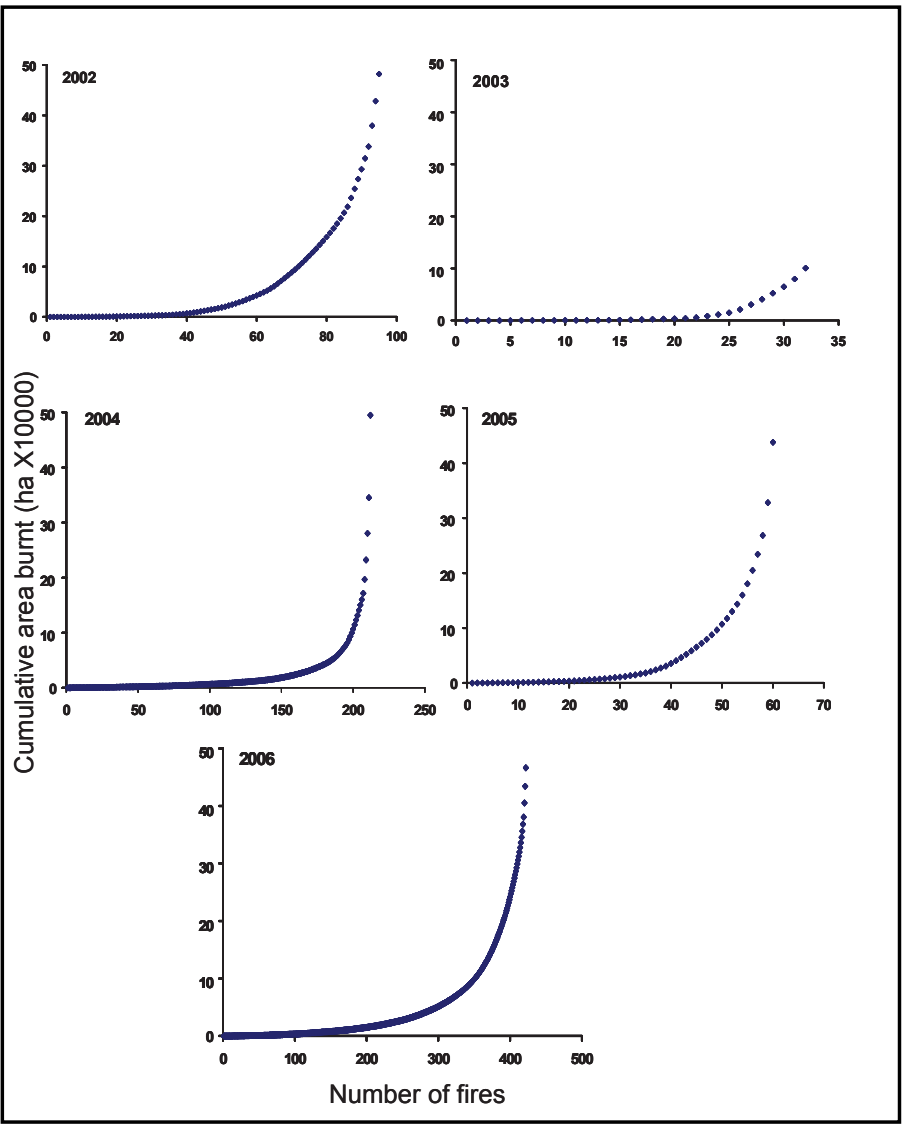

FIGURE 4

The cumulative area burnt by fires in ascending order of size in five successive years in the Kruger National Park.

a wet year, total rainfall $813 \mathrm{~mm}$ ). By comparison, the Kruger National Park completed annual burning programmes with between 0.8 and 8.5 fires for every 50000 ha of the park (see Table 2), an order of magnitude difference. The relatively small size of the Pilanesberg Park, as well as a somewhat higher mean annual rainfall $(630 \mathrm{~mm})$ may have contributed to management's ability to introduce a much finer patch burning scale.

It may well be that the Kruger National Park's new fire management approach will have to be applied for several years before the desired patterns are able to establish themselves. In the Pilanesberg, the desired levels of heterogeneity in fire patterns were only established after seven to eight years of the application of patch mosaic burning (Brockett et al. 2001). Indications are that this may be happening after four to five years in the Kruger National Park, based on fire size distributions achieved in 2006 (see Figure 3 and Table 2).

\section{The development and testing of new fire-related thresholds Process followed}

Over the past few years, the suitability of the thresholds for fire management has been regularly debated. This resulted in many of the original thresholds being incorporated into the new management approach; in other words, management would deliberately strive to create a particular fire regime in terms of area burnt and seasonal distribution of fires. It was decided that it would be desirable to monitor the variability and diversity that was achieved by these fire regimes. Two aspects were specifically identified as important: sufficient variability in fire intensity and in spatial heterogeneity. The thresholds around these two aspects were set at rather arbitrary limits, with a view to refinement once patterns became clear, in the spirit of adaptive management. It is relevant to note here that the Kruger National Park's fire management objectives centre on the maintenance of heterogeneity and variability in fire processes, and not on the achievement of any particular ecosystem goal. This is in contrast to other savanna conservation areas, such as the Hluhluwe-Imfolozi Park, where fire is used to counter bush encroachment (Balfour \& Howison 2001).

\section{Refinement of the threshold for fire intensity}

A threshold that sought to measure the degree to which fire intensity varies across the park was proposed. Variation in fire intensity was assumed to be desirable, as it has been identified as an important requirement that governs the co-existence of trees and grasses (Higgins et al. 2000). Each fire recorded on the park's database was therefore assigned to a single fire intensity class (variability is therefore gauged between, and not within, 
TABLE 4

Classes of fire intensity associated with different fuel loads and seasons of burn in the Kruger National Park (after Govender et al. 2004)

\begin{tabular}{|c|c|c|c|c|c|}
\hline \multirow{2}{*}{ SEASON OF BURN } & \multicolumn{5}{|c|}{ FUEL LOADS (KG HA-1) } \\
\hline & $<1000$ & $1000-2000$ & $2000-4000$ & $4000-6000$ & $>6000$ \\
\hline Summer (1 December - 31 March) & Very low & Low & Moderate & Moderate & Moderate \\
\hline Autumn (1 April - 30 May) & Very low & Low & Moderate & High & \\
\hline Winter (1 June -31 August) & Very low & Low & High & High & \\
\hline Spring (1 September - 30 November) & Very low & Low & Moderate & High & \\
\hline
\end{tabular}

TABLE 5

Thresholds for heterogeneity scores (\% of heterogeneous grids/all grids) for years within three rainfall classes. Grids are $5 \times 5$ cells of 100 ha each. The predicted $\%$ of the park burnt based on the relationship between rainfall and annual area burnt (van Wilgen et al. 2004)

\begin{tabular}{llll}
\hline \multirow{2}{*}{ RAINFALL CLASS } & MEAN ANNUAL RAINFALL OVER PAST & \multirow{2}{*}{ PREDICTED \% OF PARK BURNT } & \multirow{2}{*}{ HETEROGENEITY SCORE } \\
\hline 2 YRS (MM) & $<6.5$ & 10 \\
Mew & $<450$ & $6.5-20$ & 20 \\
High & $451-600$ & $>20$ & 30 \\
\hline
\end{tabular}

individual fires). The following procedure was used to assign fire intensity classes. Fuel loads were measured annually using disc pasture meters (Trollope \& Potgieter 1986) at over 500 fuel monitoring sites across the park. The fuel loads at each fire were then predicted by interpolating measured values from these monitoring sites. Each fire was assigned to an estimated fire intensity class (see Table 4), based on fuel load as well as the season of fire. Season was included because grass fuel moisture varies considerably between seasons, with significant effects on fire intensity (Govender et al. 2006). Within seasons, daily variations in weather will also have a significant effect on fire intensity. To cater for different weather on the day of the fire, fire weather is taken into account by using the Angström Index (I, see Chandler et al. 1983), calculated as:

$$
I=\left(\frac{R}{20}\right)+\left[\frac{(27-T)}{10}\right]
$$

where: $\quad I=$ Angström Index

$R$ = Relative humidity (\%) on the day of the fire

$T=$ Air temperature $\left({ }^{\circ} \mathrm{C}\right)$ on the day of the fire

The fire intensity class assigned to the fire on the basis of Table 4 was then adjusted. For $I>2$, the intensity class was reduced one level (where possible); for I between 1 and 2, the intensity class remained unchanged; and for $I<1$, the intensity class was increased to the next higher level (where possible).

It was proposed that a threshold would be reached if the area covered by fires in any one of three intensity classes (very low and low combined, moderate, and high and very high combined) constitutes $<20 \%$ or $>50 \%$ of total area burnt in a given year.

\section{Development of a threshold relating to fire heterogeneity}

This threshold sought to gauge the degree to which heterogeneous fire patterns (the spatial arrangement of burnt and unburnt areas) are established. As with fire intensity, the assumption was that reasonably heterogeneous fire patterns would be required to conserve the full suite of the park's species, which may require different fire sizes and spatial arrangements. A heterogeneity score is estimated for the park by converting the fire maps to 100 ha-grids for each year. A moving window neighbourhood of $5 \times 5$-cells is used to calculate block variety statistics for each 100 ha-grid. Each grid is scored as homogenous if all cells are either burnt or unburnt. Partially burnt grids (where some cells were burnt and others not) were scored as heterogeneous. The heterogeneity score was calculated as the number of heterogeneous grids as a percentage of all grids over the park.
Given that the proportion of the park that will burn is closely correlated with rainfall (Van Wilgen et al. 2004), heterogeneity scores would be lower in years of low rainfall. Thresholds for fire heterogeneity should therefore also vary with rainfall (see Table 5). It was proposed that a threshold would be reached if the heterogeneity score dropped below the values indicated in Table 5 for two consecutive years.

\section{Assessment of recent fire regimes against new thresholds Fire intensity}

An analysis of the fire intensities achieved over five years revealed that fires in the low and very low categories were almost non-existent (see Figure 5). In retrospect, this was not surprising, as fuel loads of $<2000 \mathrm{~kg}$ ha-1 (see Table 4) would generally be inadequate to sustain a spreading fire. Fires in the high-intensity category dominated in 2002, 2004 and 2005, while those in the moderate category dominated in 2003 and 2005 (see Figure 5). Fires in the very high category accounted for $<20 \%$ of the area burnt in most years. This distribution suggests that a threshold had been reached every year since the implementation of the new fire policy. The appropriate response in this case would probably be to recalibrate the thresholds, rather than to consider management interventions, for a number of reasons. Firstly, the expectation that at least 20\% of the area should burn each year in low-intensity fires is (with hindsight) clearly unachievable. Secondly, each fire is assigned a single intensity value, while clearly intensity can vary considerably within a single fire, especially if the fires are large (achieving a range of fire intensities in a single fire was also an important aim of point ignitions). Finally, the distribution of fire intensities in a single year does not take into account the possible need for variability in fire intensity on the same spot over successive fires. It is clear that monitoring the variability in fire intensities and their ecological impact is an issue that requires more research.

In the interim, we propose that the thresholds be reformulated to alert management to incidences where a certain class of intensity would become more dominant than may be expected. Fires in the very high category should burn at least $5 \%$ but not more than $15 \%$ of the total annual area burnt at least twice in any five-year cycle. Corresponding percentages for moderate and high-intensity fires should be 30 and $60 \%$, and 30 and $70 \%$ respectively. This would accommodate a range of achievable intensities over multiple years, without the dominance of a single category. It would also mean that, over the past five years, the thresholds for fire intensity have not been exceeded (see Figure 5). Given that these thresholds were not exceeded, management interventions would not be required at this stage. Heterogeneity

Heterogeneity scores ranged from 10 to $57 \%$ between 2002 and 2006 (see Table 6). All years except one (2003) fell into the 


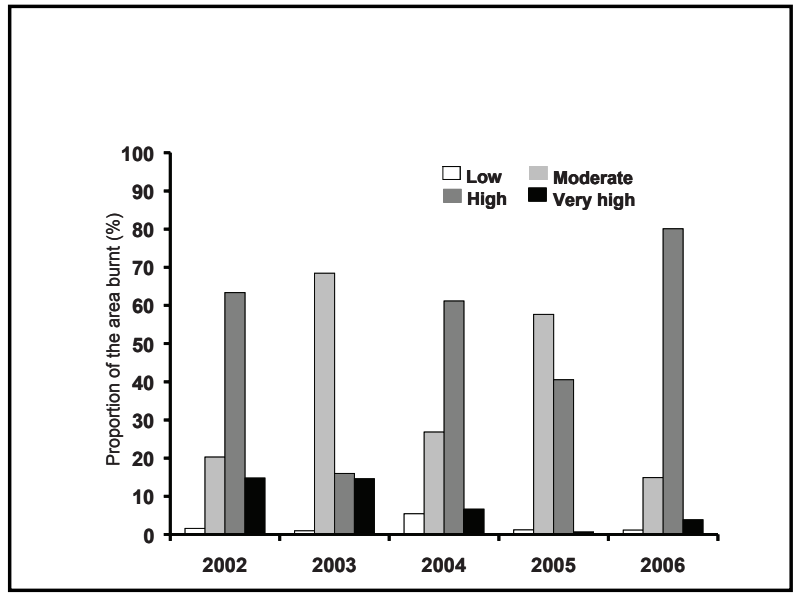

FIGURE 5

The area burnt by fires of different intensity classes (see text) in the Kruger National Park in five successive years (see Table 2 for areas burnt in each year).

medium rainfall class (see Table 6) based on the mean annual rainfall over the past two years, although annual totals ranged from low (336.7 $\mathrm{mm}$ in 2002/03) to high (708.3 $\mathrm{mm}$ in 2003/04). Thresholds for heterogeneity scores were not exceeded. The heterogeneity score threshold of $10 \%$ was reached (but not exceeded) in 2003, but the threshold requires that this must be exceeded for two consecutive years; as this was not the case, no action was required.

\section{DISCUSSION}

\section{Fire regimes and biodiversity conservation}

The fire-related thresholds in the Kruger National Park were based on the untested assumption that a diverse fire regime would promote biodiversity. In a recent critique of this approach, Parr and Andersen (2006) pointed out that the relationship between pyrodiversity and biodiversity, if any, is at best poorly understood; that in robust and resilient ecosystems (such as African savannas), a wide range of fire regimes have little effect on the ecosystem anyway; and that the dogma of "pyrodiversity begets biodiversity" is often accepted unquestioningly by managers. All of these are valid criticisms. As was pointed out in the original paper that proposed these thresholds (Van Wilgen et al. 1998), there is a need for ecological studies to assess the impact of fire regimes. The Kruger National Park's management objectives clearly recognise this need, and call for a better understanding of the links between fire, other driving factors, and biological outcomes.

A recent review of fire-related ecological research in the Kruger National Park (Van Wilgen et al. 2007) has shown that fire treatments affected vegetation structure and biomass more than species composition. Effects on vegetation were most marked in extreme treatments (annual burning, burning in the wet summer season, or long periods of fire exclusion), and were greater in areas of higher rainfall. Faunal communities and soil physiology were largely unaffected by fire. These findings indicate that the fire regimes that currently dominate the Kruger National Park's ecosystems will not produce undesired effects, as they do not include long fire-free periods or large areas burnt in summer. The impact of changes in fire regimes are also more marked in areas of higher rainfall (Van Wilgen et al. 2007). It is relevant to note here that Balfour and Howison's (2001) finding that fire management had a significant influence on the annual area burnt is in contrast to the finding in the Kruger National Park, where the area burnt each year was related to variations in rainfall and not management (Van Wilgen et al. 2004). The mean annual rainfall in Hluhluwe-Imfolozi Park is about $850 \mathrm{~mm}$, significantly higher than that of the Kruger National Park, with a mean around $550 \mathrm{~mm}$. Where mean annual rainfall is $<650 \mathrm{~mm}$, woody cover in savannas is constrained by moisture availability; above $650 \mathrm{~mm}$, the development of a closed canopy is possible, and largely prevented by fire and herbivory (Bond et al. 2003, Sankaran et al. 2005). This suggests that a different management approach may be appropriate in those parts of the Kruger National Park where mean annual rainfall exceeds $650 \mathrm{~mm}$. It may well be necessary to delineate these higherrainfall areas, and to develop specific fire-related thresholds for these areas, where the impact on biodiversity may be more marked (see Recommendations).

\section{Fire and elephants}

Concern has been expressed about declines in large trees in the Kruger National Park. These declines are at least in part due to fire, and interactions between fire and herbivory by elephants (Eckhardt et al. 2000, Edkins et al. 2007). The exclusion of one of either fire or elephants, and the presence of the other, both result in the dominance of large trees; the co-occurrence of both apparently erodes the number of large trees (Van Wilgen $e t$ al. 2003). Elephants do considerable damage to woody vegetation, and increase the susceptibility of trees to damage during fires (see Figure 6). It is therefore tempting to consider either the manipulation of fire regimes, or reductions in elephant numbers, as possible means of slowing or preventing declines in large trees in the presence of elephants. However, there are a number of underlying principles that need to be considered before such interventions can be proposed (Owen-Smith et al. 2006). These include: (i) the absence of a benchmark against which to judge an "ideal" vegetation state for the park; (ii) the possibility that large trees present today may have established during a time when elephants had been eliminated from the area as has happened elsewhere (Dublin et al. 1990), and which is itself an unnatural situation; and (iii) the fact that observed declines in large trees took place despite limiting the elephant population through culling for over three decades. OwenSmith et al. (2006) also point out that manipulation of one component of an ecosystem is likely to be ineffective because poorly understood feedbacks are not taken into account and that "perpetual tinkering" to meet aesthetic objectives should be avoided. There is also growing recognition that ecosystems are in a state of flux (Rogers 2003) and that stable or semi-stable states are both unattainable and undesirable. Owen-Smith et al. (2006) have proposed that thresholds for the maintenance of tree populations need to be made spatially explicit, for example so that the elimination of large trees can be tolerated in some areas as long as they survive in others. Clearly, the issue of

TABLE 6

Heterogeneity scores for fire patterns measured on grids of 9 cells $(100 \times 100$ ha) over 5 years in the Kruger National Park. Rainfall is an average for the whole park. The predicted $\%$ of the park burnt based on the relationship between rainfall and annual area burnt (van Wilgen et al. 2004)

\begin{tabular}{llllll}
\hline YEAR & $\begin{array}{l}\text { MEAN ANNUAL } \\
\text { RAINFALL OVER } \\
\text { PREVIOUS 2 YEARS (MM) }\end{array}$ & $\begin{array}{l}\text { PREDICTED \% } \\
\text { OF PARK BURNT }\end{array}$ & $\begin{array}{l}\text { ACTUAL \% OF } \\
\text { PARK BURNT }\end{array}$ & $\begin{array}{l}\text { RAINFALL } \\
\text { CLASS }\end{array}$ & $\begin{array}{l}\text { HETEROGENEITY } \\
\text { SCORE }\end{array}$ \\
\hline 2002 & 520 & 14 & 26 & Medium & 35 \\
2003 & 407 & 7 & 5 & Low & 10 \\
2004 & 523 & 15 & 26 & Medium & 49 \\
2005 & 549 & 16 & 23 & Medium & 28 \\
2006 & 512 & 14 & 29 & Medium & 57 \\
\hline
\end{tabular}




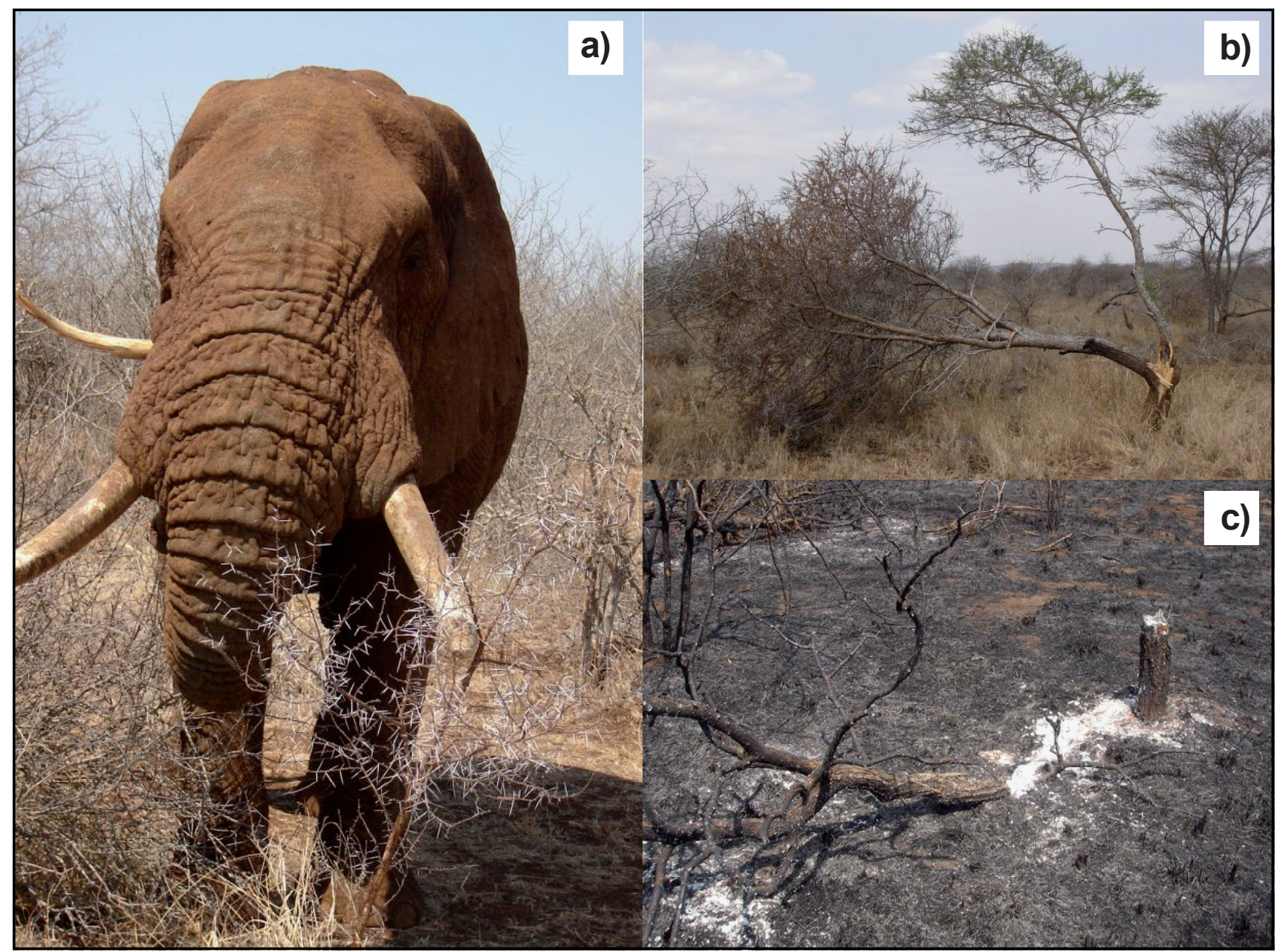

FIGURE 6

Impact of elephants on woody vegetation in combination with fire in the Kruger National Park. a) = elephants are capable of breaking large woody stems from living trees; b) $=$ typical elephant damage to Acacia nigrescens tree; $c)=\begin{gathered}\text { specimen of A. nigrescens that has been burnt off in a fire following elephant damage to the stem. Such a tree would } \\ \text { normally survive fires of moderate or even high intensity. }\end{gathered}$

interactions between fire regimes, herbivory and other factors requires better understanding if concrete recommendations about the use of fire are to be made.

\section{The seasonal distribution of fires}

Early fire regimes in the Kruger National Park could arguably have been driven predominantly by lightning ignitions, which would have occurred late in the dry season. While humans would also have provided a source of ignitions for a very long time, their population levels would have been orders of magnitude lower than the modern situation, and it is therefore possible that lightning-ignited fires could have dominated the environment in which the park's biota evolved. The new firemanagement approach seeks to spread fires across the dry season. Such shifts in fire season (from late-season, relatively low-intensity fires to more intense, dry-season fires) could exacerbate tree mortality in combination with elephants. It has frequently been argued (Biggs \& Potgieter 1999, Kennedy \& Potgieter 2003) that a shift back to late-season burns would be desirable to mimic fire regimes under conditions of low human occupation. In reality, however, the current levels of human influence would prevent this (Van Wilgen et al. 2004). Global climate change may also increase the risk of very intense dryseason fires if such change results in conditions of increased fire danger (although this has yet to be predicted), resulting in higher levels of mortality, both in elephant-damaged trees and in animals (for example, several elephants and white rhinoceros succumbed to high-intensity fires in August 2007). It has also been suggested (Whyte 2006) that extensive, early dry-season fires may have been responsible (at least in part) for declines in rare antelope (roan, sable, tsessebe and eland), because of exposure to unfavourable burnt areas for longer periods. Early dry-season fires may well be a reality though, given the abundance of new ignition sources in the environment. While the source of ignition has no biological significance (Van Wilgen et al. 1998) (fires at the same frequency, season and intensity will have the same effect regardless of how they were ignited), the timing of ignitions is important. Human-ignited fires are more likely to occur earlier in the dry season, and lightning fires later. The conditions under which these fires burn are different and they will have different effects. While this question is also deserving of further investigation, the reality of increased dry-season ignitions will have to be taken into account in the pragmatic management of the park.

\section{RECOMMENDATIONS}

We recommend that the point-ignition fire-management approach be continued. It may be desirable, however, to attempt to be more aggressive when it comes to early-season burns. If park managers are able to burn larger areas early in the season (April to June), this may assist the development of a mosaic of burnt areas that will limit later fires, and also create refugia for wildlife from later, more intense fires.

We also recommend that research be encouraged to address the important questions identified here, so that future thresholds can be framed in terms of ecologically meaningful measures, as 
opposed to surrogate measures of the fire regime. These would include (i) the ecological importance of fire intensity over space and time, and the development of meaningful and manageable ways to assess this at an appropriate scale; (ii) the ecological importance, if any, of variability of spatial patterns of fire; and (iii) the interaction between elephants and fire, particularly in terms of its effects on woody vegetation.

We would further recommend that areas of higher rainfall (>650 mm mean annual rainfall) be delineated, and that specific fire-related thresholds be developed for these areas. We also support the recommendation (Owen-Smith et al. 2006) that thresholds for the maintenance of tree populations need to be made spatially explicit.

Finally, it will remain important to record, monitor and analyse fire patterns as they develop. The examination of fire regimes over time is relatively easy, given that the park has an excellent fire database. It has also provided an excellent basis for adaptive learning in the past, and promises to continue to do so. As such, it has a pivotal role to play in ongoing adaptive management.

\section{ACKNOWLEDGEMENTS}

The first author thanks South African National Parks for supporting this work, and the CSIR for research funding. Dr Harry Biggs provided useful input into the development of ideas for new fire-related thresholds.

\section{REFERENCES}

Balfour, D.A. \& Howison, O.E. 2001. Spatial and temporal variation in a mesic savanna fire regime: responses to variation in annual rainfall. African Journal of Range $\mathcal{E}$ Forage Science 19: 43-51.

Biggs, H.C. \& Potgieter, A.L.F. 1999. Overview of the fire management policy of the Kruger National Park. Koedoe 42: 101-110.

Biggs, H.C. \& Rogers, K.H. 2003. An adaptive system to link science, monitoring and management in practice. In: Du Toit, J.T., Rogers, K.H. \& Biggs, H.C. (eds). The Kruger experience: Ecology and management of savanna heterogeneity. Washington, Island Press. Pp. 59-80.

Bond, W.J. \& Archibald, S. 2003. Confronting complexity: fire policy choices in South African savanna parks. International Journal of Wildland Fire 12: 381-389.

Bond, W.J, Midgley, G.F. \& Woodward, F.I. 2003. What controls South African vegetation - climate or fire? South African Journal of Botany 69: 1-13.

Brockett, B.H., Biggs, H.C. \& Van Wilgen, B.W. 2001. A patch mosaic burning system for conservation areas in southern Africa. International Journal of Wildland Fire 10:169-183.

Chandler, C., Cheney, N.P., Trabaud, T.L. \& Williams D. 1983. Fire in forestry. Volume 1. Forest fire behaviours and effects. New York, John Wiley.

Dublin, H.T., Sinclair, A.R.E. \& Mcglade, J. 1990. Elephants and fire as causes of multiple states in the Serengeti-Mara Woodlands. Journal of Animal Ecology 59: 1147-1164.

Eckhardt, H.C., Van Wilgen, B.W. \& Biggs, H.C. 2000. Trends in woody vegetation cover in the Kruger National Park, South Africa, between 1940 and 1998. African Journal of Ecology 38: 108-115.

Edkins, M.T., Kruger, L.M., Harris, K.\& Midgley, J.J. 2007. Baobabs and elephants in Kruger National Park: nowhere to hide. African Journal of Ecology 38: 108-115.
Govender, N., Trollope, W.S.W. \& Van Wilgen, B.W. 2006. The effect of fire season, fire frequency, rainfall and management on fire intensities in savanna vegetation in South Africa. Journal of Applied Ecology 43: 748-758.

Higgins, S.I., Bond, W.J. \& Trollope, W.S.W. 2000. Fire, resprouting and variability: a recipe for grass-tree coexistence in savanna. Journal of Ecology 88: 213-229.

Kennedy, A.D. \& Potgieter, A.L.F. 2003. Fire season affects size and architecture of Colophospermum mopane in southern African savannas. Plant Ecology 167: 179-192.

Mentis, M.T. \& Bailey, A.W. 1990. Changing perceptions of fire management in savanna parks. Journal of the Grassland Society of Southern Africa 7: 81-85.

Owen-Smith, N., Kerley, G.I.H., Page, B., Slowtow, R. \& Van Aarde, R.J. 2006. A scientific perspective on the management of elephants in the Kruger National Park and elsewhere. South African Journal of Science 102: 389-394.

Parr, C.L. \& Andersen, A.N. 2006. Patch mosaic burning for biodiversity conservation: a critique of the pyrodiversity paradigm. Conservation Biology 20: 1610-1619.

Rogers, K.H. 2003. Adopting a heterogeneity paradigm: Implications for management of protected savannas. In: Du Toit, J.T., Rogers, K.H. \& Biggs, H.C. (eds). The Kruger experience: Ecology and management of savanna heterogeneity. Washington, Island Press. Pp. 41-58.

Sankaran, M., Hanan, N.P., Scholes, R.J., Ratnam, J., Augustine, D.J., Cade, B.S., Gignoux, J., Higgins, S.I., Le Roux, X., Ludwig, F., Ardo, J., Banyikwa, F., Bronn, A., Bucini, G., Caylor, K.K., Coughenour, M.B., Diouf, A., Ekaya, W., Feral, C.J., February, E.C., Frost, P.G.H., Hiernaux, P., Hrabar, H., Metzger, K.L., Prins, H.H.T., Ringrose, S., Sea1, W., Tews, J., Worden, J. \& Zambatis, N. 2005. Determinants of woody cover in African savannas. Nature 438: 846-849.

Scholes, R.J. \& Walker, B.H. 1993. An African savanna: Synthesis of the Nylsvley study. Cambridge, Cambridge University Press.

Trollope, W.S.W. \& Potgieter, A.L.F. 1986. Estimating grass fuel loads with a disc pasture meter in the Kruger National Park. Journal of the Grassland Society of Southern Africa 3: 148-152.

Van Langevelde, F., Van de Vijver, C.A.D.M., Kumar, L., Van de Koppel, J., De Ridder, N., Van Andel, J., Skidmore, A.K., Hearne, J.W., Stroosnijder, L., Bond, W.J., Prins, H.T. \& Rietkerk, M. 2003. Effects of fire and herbivory on the stability of savanna ecosystems. Ecology 84: 337-350.

Van Wilgen, B.W., Biggs, H.C. \& Potgieter, A.L.F. 1998. Fire management and research in the Kruger National Park, with suggestions on the detection of thresholds of potential concern. Koedoe 41: 69-87.

Van Wilgen, B.W., Govender, N.\& Biggs, H.C. 2007. The contribution of fire research to fire management: A critical review of a long-term experiment in the Kruger National Park, South Africa. International Journal of Wildland Fire 16: 519-530.

Van Wilgen, B.W., Govender, N., Biggs, H.C., Ntsala, D. \& Funda, X.N. 2004. Response of savanna fire regimes to changing fire management policies in a large African national park. Conservation Biology 18: 1533-1540.

Van Wilgen, B.W., Trollope, W.S.W., Biggs, H.C., Potgieter, A.L.F., \& Brockett, B.H. 2003. Fire as a driver of ecosystem variability. In: Du Toit, J.T., Rogers, K.H. \& Biggs, H.C. (eds). The Kruger experience: Ecology and management of savanna heterogeneity. Washington, Island Press. Pp. 149-170.

Whyte, I.J. 2006. Rare antelope in the Kruger National Park: Trends, current status and options for future management. Scientific Report 05/2006, South African National Parks, Skukuza. 